\title{
Rikollisuus vai rasismi? Poliisiväkivalta ja sen tutkimus Yhdysvalloissa
}

\author{
JUKKA SAVOLAINEN
}

Tilastojen mukaan USA:n poliisit surmaavat kansalaisia huomattavasti enemmän kuin poliisit muissa länsimaissa. Vuonna 2019 yli tuhat amerikkalaista kuoli poliisin toiminnan seurauksena. Vastaava luku naapurimaassa Kanadassa oli 36 (Jones \& Sawyer, 2020). Väkilukuun suhteutettuna amerikkalaisilla on yli kolme kertaa suurempi riski kuolla poliisin surmaamana kuin kanadalaisilla ja yli 25 kertaa suurempi riski kuin saksalaisilla.

Tilanne heijastanee ampuma-aseiden yleisyyttä sekä poliisin että väestön keskuudessa. Taustalla voi myös olla poliisin ammattitaidon puutetta. Toisin kuin Suomessa ja useimmissa muissa länsimaissa, Yhdysvalloissa on erittäin hajanainen ja paikallisesti johdettu poliisivoima. Maassa toimii lähes 18000 itsenäistä poliisilaitosta, joista noin puolet koostuu alle kymmenen poliisin kokoisista yksiköistä (Bureau of Justice Statistics, 2016). On sangen tavallista, että pieniä poliisilaitoksia johtaa paikallisvaaleissa valittu "kovanaamainen" sheriffi. Suomessa poliisikoulutus on alempi korkeakoulututkinto, jonka suoritusaika kestää noin kolme vuotta. Yhdysvalloissa ei ole kansallista standardia, vaan koulutus vaihtelee osavaltioittain. Georgian osavaltiossa minimikoulutus kestää vain 11 viikkoa, mikä on kolme kertaa lyhyempi kuin parturi-kampaajan perustutkinto samassa osavaltiossa (Semuels, 2020).

Kolmas mahdollinen selitys USA:n poliisin väkivaltaisuudelle on rasismi. Julkisessa keskustelussa on esitetty väitteitä, jonka mukaan poliisit ampuvat tummaihoisia amerikkalaisia herkemmin kuin valkoihoisia. Käsittelen tässä puheenvuorossa amerikkalaista tutkimusta poliisiväkivallan syrjivyydestä. Katsaukseni valossa Yhdysvalloissa vallitsee syvä ristiriita tieteellisen evidenssin ja tiedotusvälineiden tuottaman mielikuvan välillä.

\section{Suhteessa mihin?}

Kun Donald Trump totesi televisiohaastattelussa kesällä 2020, että “poliisi surmaa enemmän valkoihoisia" kuin tummaihoisia kansalaisia, hän oli teknisesti ottaen oikeassa. Vuonna 2018 poliisi ampui Yhdysvalloissa kuoliaaksi 456 valkoihoista ja 229 mustaksi luokiteltua henkilöä (The Washington Post, 2020). Valkoisia uhreja oli siis noin kaksi kertaa enemmän. Trumpin lausumaa pidettiin kuitenkin harhaanjohtavana, koska mustien väkilukuun suhteutettu kuolleisuus on yli kaksi kertaa korkeampi kuin valkoisilla. Mustien riski kuolla poliisin luodista on siis huomattavasti valkoihoisia suurempi. Mutta onko surmattujen määrän suhteuttaminen väestön määrään paras tapa vertailla ryhmiä? Esimerkiksi miesten riski tulla surmatuksi on 18 kertaa suurempi kuin naisten, mikä heijastaa sukupuolten välistä eroa rikollisuudessa, erityisesti vakavassa väkivaltarikollisuudessa. Tuskin kukaan väittää, että poliisi syrjii miehiä.

Jos tarkoituksena on kuvata riskiä joutua poliisin väkivallan uhriksi, on järkevää suhteuttaa lukumäärät siihen, kuinka usein ryhmän 
jäsenet tulevat tekemisiin poliisin kanssa. Poliisin päätös käyttää voimakeinoja ei ole sattumanvarainen vaan riippuu esimerkiksi siitä, onko uhri rikkonut lakia ja miten hän itse reagoi poliisin toimintaan tällaisissa tilanteissa. Vuonna 2018 mustat tekivät yli puolet (52\%) Yhdysvaltojen kaikista henkirikoksista (U.S. Department of Justice, 2020). Luku on varsin korkea, kun huomioidaan, että mustien osuus koko väestöstä on vain 12 prosenttia. Mustien väkilukuun suhteutettu henkirikollisuus on kuusinkertainen valkoisiin verrattuna, mutta heidän todennäköisyytensä kuolla poliisin luodista on siis alle kolminkertainen. Tästä näkökulmasta katsoen mustien riski kuolla poliisin luodista on siis pienempi kuin valkoisten. Rikollisuus on kuitenkin vain yksi tekijä, joka vaikuttaa väestöryhmien välisiin eroihin poliisiväkivallan riskissä. Paras tapa arvioida syrjinnän merkitystä olisi tietenkin huomioida kaikki muut poliisin käyttäytymiseen vaikuttavat tekijät, mikä on käytännössä erittäin vaikea haaste.

\section{Vakiointi ja valikointi}

Harvardin yliopiston taloustieteen professori Roland Fryer - joka on itse afroamerikkalainen - on julkaissut tutkimuksen, jossa sovellettiin tilastollisia monimuuttujamenetelmiä neljään toisistaan riippumattomaan aineistoon (Fryer, 2019). Tutkimuksessa havaittiin, että mustilla ja latinoilla oli valkoihoisia suurempi riski joutua poliisin lievempien voimakeinojen kohteeksi, mutta kun tarkastelu rajoitettiin koskemaan kaikkia ampumisia (ei siis pelkästään kuolettavia), ryhmien välisiä eroja ei havaittu. Analyyseissa vakioitiin epäiltyjen ikä, sukupuoli, rikoshistoria ja sosioekonominen asema, poliisin demografiset ominaisuudet sekä tilanteen piirteitä, esimer- kiksi epäillyn aseistus. Tällaisessa monimuuttujamallissa mustilla oli hieman valkoisia pienempi riski joutua ammutuksi, mutta ero ei ollut tilastollisesti merkitsevä.

Fryerin artikkeli ilmestyi vuonna 2019 julkaisussa Journal of Political Economy. Seuraavana vuonna Steven Durlauf ja James Heckman (2020) julkaisivat samassa lehdessä kriittisen kommentin, jonka mukaan Fryerin tutkimuksen perusteella ei voida päätellä, että poliisi ampuu valko- ja tummaihoisia tasapuolisesti. Heckman on taloustieteen nobelisti, jonka keskeinen tutkimuksen kohde on ollut niin kutsuttu valikoitumisharha (selection bias). Heidän mukaansa Fryerin tutkimus on esimerkki tästä ongelmasta, koska aineisto rajoittuu tapauksiin, joissa epäilty on joutunut poliisin kohtaamaksi. Asetelma ei siis huomioi, että mustien todennäköisyys valikoitua poliisin "haaviin" voi olla paljon suurempi kuin valkoisten.

Mikäli oletus rasistisesta valikoitumisharhasta pitää paikkansa, tilastollinen vakiointi ei riitä poistamaan ryhmien välisiä eroja. Voidaan esimerkiksi ajatella, että aggressiivisten, psykoottisten tai muulla tavoin vaikeiden tapausten osuus on huomattavasti suurempi valkoihoisten kuin tummaihoisten asiakkaiden joukossa. On siis mahdollista, että poliisin voimatoimien kohteeksi joutuvat tummaihoiset ovat keskimäärin vähemmän vaarallisia kuin valkoiset. Jos tällaiseen aineistoon perustuva tutkimus osoittaa, että valkoisilla ja mustilla on samanlainen riski kuolla poliisin luodista, olisi virheellistä päätellä, että poliisi kohtelee väestöryhmiä tasavertaisesti.

Vaikkakin analyyttisesti täysin korrekti, Durlaufin ja Heckmanin kommentti on sikäli erikoinen, että - kuten Fryer (2020) toteaa vastineessaan - huomattava osa hänen artikkelistaan on omistettu tämän nimenomaisen 
metodologisen ongelman käsittelyyn. Kysymystä tarkasteltiin empiirisesti muun muassa vertailemalla kahta eri valikoitumisprosessia. Ensimmäisessä poliisi oli hälytetty paikalle hätänumeron kautta. Näissä tilanteissa poliisilla ei ole mahdollisuutta valikoida asiakkaitaan. Toisessa prosessissa asiakaskontakti johtui poliisin omasta harkinnasta, eli subjektiivisesta päätöksestä puuttua tilanteeseen. Jos poliisin rasismi on merkittävä ongelma, on loogista olettaa, että etnisten ryhmien väliset erot tapausten kuolettavuudessa olisivat suurempia kohtaamisissa, jotka syntyivat poliisin omasta aloitteesta. Tällaista eroa ei tutkimuksessa kuitenkaan havaittu. Fryer korostaa että - toisin kuin Durlauf ja Heckman antavat ymmärtää - valtaosa konfrontaatioista, joissa poliisi ampui siviiliä, sai alkunsa ulkopuolisesta hälytyksestä. Tämä on tärkeä huomio, koska näissä tapauksissa kontaktiin valikoituminen ei siis johdu tapausta selvittävän poliisin harkinnasta.

Valikoitumisharhalle alttiista tutkimisasetelmasta huolimatta on kiinnostavaa tarkastella, mitä mustille ja valkoisille tapahtuu poliisien käsittelyssä. Mikäli oletetaan, että poliisit syrjivät tummaihoisia pysäyttämällä heitä lievemmistä rikkomuksista kuin valkoihoisia, on johdonmukaista olettaa, että rasismi ei pääty tähän, vaan sen tulisi näkyä myös siinä, miten poliisi kohtelee asiakkaita pidätyksen yhteydessä. On mielenkiintoista, että Fryer havaitsi ryhmien välisiä eroja ainoastaan poliisin lievemmässä voimankäytössä, mutta ei poliisin päätöksessä ampua. Tämän tuloksen perusteella Fryerin aineisto kykenee osoittamaan diskriminaatiota, mikäli sellaista esiintyy.

Vaikka Fryerin tutkimus on metodologisesti vahva, se on tuskin viimeinen sana tässä kirjallisuudessa. On mahdollista, että laadukkaampi tutkimus osoittaa Fryerin johtopää- tökset vääriksi. Mutta vallitsevan tiedon perusteella olisi virheellistä yksioikoisesti väittää, että Yhdysvalloissa mustilla olisi valkoisia suurempi riski kuolla poliisin luodista, kun otetaan huomioon kaikki tähän riskiin vaikuttavat tekijät. On totta, että varsin monissa tutkimuksissa on päädytty siihen, että Yhdysvalloissa poliisi kohtelee mustia eriarvoisesti. Suurin osa niistä perustuu kuitenkin puhtaasti kuvaileviin tutkimusasetelmiin, joiden perusteella ei voida tehdä kausaalisia johtopäätöksiä suuntaan tai toiseen (Neil \& Winship, 2019).

\section{Tieto ja tietoisuus}

Tieteellisesti adekvaatin evidenssin puute ei ole kuitenkaan estänyt Yhdysvaltoja ajautumasta tilanteeseen, jossa massiiviset kansanjoukot, julkisuuden henkilöt ja mielipidejohtajat pitävät itsestään selvänä, että poliisit surmaavat mustaihoisia kansalaisia huimasti herkemmin kuin valkoihoisia. Vuoden 2021 helmikuussa julkaistun kyselyn mukaan yli puolet edistysmielisistä ("very liberal") amerikkalaisista arvioivat, että vähintään tuhat aseistamatonta (unarmed) afroamerikkalaista kuolee poliisin käsittelyssä vuoden aikana (McCaffree \& Saide, 2021). Tämä arvio on 10-100 kertaa korkeampi luku kuin erilaisiin tutkimusaineistoihin perustuvat tiedot. Mustien todellinen osuus poliisin luotiin menehtyneistä on siis noin 25 prosenttia, mutta kansalaisten arviot mustien osuudesta vaihtelevat 40-60 prosentin välillä poliittisen orientaation mukaan. Siis jopa äärikonservatiiviset amerikkalaiset liioittelevat afroamerikkalaisten suhteellista riskiä kuolla poliisin luodista.

Nämä uskomukset perustuvat tiedotusvälineiden ja sosiaalisen median tuottamaan informaatioon, jossa ylikorostuvat rotukysymyksen kannalta tulenarat tapaukset. 
Georgian valtionyliopiston jatko-opiskelija Zach Goldberg (2020) selvitti, kuinka ahkerasti erilaiset uutiskanavat tiedottivat tapauksista, joissa poliisi tappoi aseettoman mustan, verrattuna vastaaviin tilanteisiin, joissa surmattu oli valkoinen. Analyysi osoitti, että mustia uhreja koskevista tapauksista uutisoitiin yhdeksän kertaa enemmän. Goldberg havaitsi, että valkoisista uhreista kolmannes jäi täydelliseen uutispimentoon, kun vastaava osuus mustilla oli vain 12 prosenttia.

Afroamerikkalainen poleemikko Coleman Hughes (2020) onkin todennut, että jokaiselle mustalle poliisin väkivallan uhrille löytyy valkoihoinen vastine. Mutta julkisen keskustelun painotusten vuoksi valkoisten uhrien nimet eivät ole suuren yleisön tiedossa samalla tavalla kuin vaikkapa George Floyd tai Michael Brown, joiden kuolemat johtivat mittaviin mellakoihin. Tony Timpa oli valkoihoinen 32-vuotias mies, joka kuoli Dallasin poliisin käsittelyssä vuonna 2016 tavalla, joka muistuttaa George Floydin kuolemaa. Molemmat uhrit olivat ahdistuneita ja päihteiden vuoksi sekavassa tilassa, kun poliisit laittoivat heidät käsirautoihin, kaatoivat maahan ja estivät heitä liikkumasta polvella ylävartaloon painaen. George Floydin tavoin Tony Timpa menetti tajuntansa ja tukehtui tässä asennossa. Molemmat tapaukset tallennettiin videolle, mutta Timpan kuolema ei herättänyt suurta mielenkiintoa mediassa, eikä häntä pahoinpidelleitä poliiseja asetettu syytteeseen.

On valitettavaa, että julkista keskustelua vinouttava "valikoitumisharha" ei ole herättänyt juurikaan mielenkiintoa alan tutkijoiden keskuudessa. Metodologisesti sofistikoituneet akateemikot väittelevät siitä, miten asiat ovat, mutta tuntuvat unohtaneen, että joskus on vähintään yhtä tärkeää ymmärtää miltä asiat näyttävät. Sosiologiassa tämä periaate tunnetaan nimellä Thomas-teoreema: "If men define situations as real, they are real in their consequences"; eli uskomuksilla on todelliset seuraamukset riippumatta siitä, perustuvatko ne faktaan vai fiktioon.

George Floydin kuolemaa seuranneen protestiliikehdinnän vanavedessä Minneapolisin kaupunginvaltuusto lupasi lakata rahoittamasta poliisin toimintaa. Vaikka valtuusto sittemmin perui tämän radikaalin päätöksen, on hyvä tuoda esiin, että kaupungin afroamerikkalaiset asukkaat vastustivat poliisivoimien kutistamista enemmän kuin valkoiset (The Star Tribune, 2020). Alustavat tiedot viittaavat siihen, että kaupungin poliisien määrä on vähentynyt rahoituksesta riippumatta poliisivastaisen ilmapiirin seurauksena, mikä on puolestaan johtanut väkivaltarikollisuuden huomattavaan kasvuun (Sharp, 2020). Ei ole vaikea arvata, mitkä väestöryhmät kärsivät tästä lopputuloksesta eniten. Vuoden 2021 alussa - noin kolme viikkoa ennen Floydin kuolemaa koskevan oikeusprosessin alkua - Minneapolis myönsi 6,4 miljoona dollaria uusien poliisien palkkaamiseksi (The Associated Press, 2021).

\section{Universaaleja uudistuksia}

USA on jyrkästi epätasa-arvoinen yhteiskunta, jossa merkittävällä osalla väestöä menee hyvin: heillä on korkea elintaso, hyvä koulutus ja työpaikka, jonka etuihin kuuluvat kattava terveysvakuutus ja eläkerahasto. Pienemmällä, mutta huomattavan suurella osalla amerikkalaisia menee todella huonosti: he elävät äärimmäisessä köyhyydessä minimipalkalla, ilman kunnollista terveydenhuoltoa ja mahdollisuuksia osallistua korkeamman asteen koulutukseen. Suhteettoman suuri osa mustasta väestöstä kuulu tähän huono-osaisten joukkoon. Tästä tosiasiasta käytetään toisinaan termiä "rakenteellinen rasismi", mikä 
eroaa perinteisestä rasismista siten, että rakenteellinen rasismi ei edellytä avoimen rasistisia asenteita tai uskomuksia valtaväestön keskuudessa. Tällaisessa yhteiskunnassa ryhmien välinen epätasa-arvo toteutuu vakiintuneen järjestelmän uusintamana.

Tehokkain tapa vähentää rakenteellista eriarvoisuutta on muuttaa vallitsevia rakenteita, esimerkiksi parantamalla sosiaaliturvaa ja koulutusmahdollisuuksia. Minimipalkan korottaminen on osoittautunut historiallisen aineiston valossa tehokkaaksi keinoksi paitsi vähentää köyhyyttä, myös kaventaa rodullistettujen väestöryhmien välisiä tuloeroja Yhdysvalloissa (Derenoncourt \& Montialoux, 2020). Fryerin tavoin katson, että mustien suurempi riski kuolla poliisin luodista johtuu ennen muuta heidän epäsuhtaisesta osallisuudestaan väkivaltaiseen rikollisuuteen Yhdysvaltojen suurkaupunkialueilla. Paras tapa ehkäistä näitä traagisia tapauksia on puuttua rakenteelliseen rasismiin ja parantaa köyhien amerikkalaisten elinoloja. Myös poliisin toiminnassa on parantamisen varaa. Uskon, että sitä voidaan muuttaa kehittämällä kansallisia ja paikallisia "parhaita käytäntöjä", mikä luonnollisesti edellyttää satsausta kunnolliseen poliisikoulutukseen.

Ilmastonmuutoksen pysäyttämiseen tähtäävä kansaliike perustuu avoimeen ja puolueettomaan tieteellisen tietoon, jonka valossa on ilmeisen selvää, että ihmisten toiminta maapallolla on vaikuttanut ilmaston lämpenemiseen. Tieteellisestä evidenssistä huolimatta monet ihmiset eivät kannata kestävän kehityksen politiikkaa vaan haluavat jatkaa entiseen tapaan. Jotkut heistä eivät usko tai halua uskoa tieteelliseen konsensukseen ilmaston lämpenemisestä ja sen syistä. Faktat ovat kuitenkin ilmaston puolesta taistelevien puolella. Oletan, että tämä on keskeinen syy, jonka vuoksi ympäristöliike on edennyt voitosta voittoon vuosikymmenien saatossa. Olisi suotavaa, että tieteellinen evidenssi näyttelisi yhtä merkittävää osaa sosiaaliseen oikeudenmukaisuuteen tähtäävien liikkeiden parissa.

\section{KIRJALLISUUS}

Bureau of Justice Statistics (2016). National Sources of Law Enforcement Employment Data. U.S. Department of Justice: Office of Justice Programs. Saatavilla: https://www.bjs.gov/content/pub/pdf/nsleed.pdf

Derenoncourt, E. \& Montialoux, C. (2020, 25/10). To Reduce Racial Inequality, Raise the Minimum Wage. The New York Times. Saatavilla: https://nyti.ms/3jqs8Jj

Durlauf, S. N., \& Heckman, J. J. (2020). An Empirical Analysis of Racial Differences in Police Use of Force: A Comment. Journal of Political Economy, 128(10), 3998-4002.

Fryer Jr, R. G. (2019). An empirical analysis of racial differences in police use of force. Journal of Political Economy, 127(3), 1210-1261.

Fryer Jr, R. G. (2020). An Empirical Analysis of Racial Differences in Police Use of Force: A Response. Journal of Political Economy, 128(10), 4003-4008.

Goldberg, Z. (2020, 4/8). How the media led the great racial awakening. Tablet. Saatavilla: https://www.tabletmag.com/sections/news/articles/media-great-racial-awakening

Hughes, Coleman (2020, 14/6). Stories and data: Reflections on race, riots, and police. City Journal. Saatavilla: https://www.city-journal.org/reflectionson-race-riots-and-police

Jones, A. \& Sawyer, W. (2020, 5/6). Not just "a few bad apples": U.S. police kill civilians at much higher rates than other 
countries. Prison Policy Initiative. Saatavilla: https://www.prisonpolicy.org/blog/2020/06/05/policekillings/

McCaffree, K. \& Saide, A. (2021). How Informed are Americans about Race and Policing? Skeptic Research Center, CUPES-007.

Neil, R., \& Winship, C. (2019). Methodological challenges and opportunities in testing for racial discrimination in policing. Annual Review of Criminology, 2, 73-98.

Semuels, A. (2020, 20/11). As Police Departments Outsource Officer Training to Save Money, Society May Be Paying the Price. Time Magazine. Saatavilla: https://time.com/5901726/police-training-academies/?fbclid=IwAR1943iQzchUG-S0Z5v2MKOuAaP1xkkgVFfzm7YWjALBwfibBk_RUIDEDI Sharp, R. (2020, 14/11). Refund the police! Daily Mail. Saatavilla: https://www.dailymail.co.uk/news/article-8948381/Minneapolis-authorizes-500k-hire-copsforces-officers-leave-crime-surges.html The Associated Press (2021, 13/2). Minneapolis to Spend $\$ 6.4 \mathrm{M}$ to Recruit More Police Officers. The Associated Press. Saatavilla: https://apnews.com/article/usnews-police-minneapolis-racial-injusticeb55590dc98ff22a5b15210eba341c0e1

The Star Tribune (2020, 16/8). Mayor Frey, the City Council and defunding Minneapolis police. The Star Tribune. Saatavilla: https://www.startribune.com/minnesotapoll-full-results-minneapolis-defund-police-department-city-council-mayor-jacob-frey-dismantle-reform-george-floydmpd/572109911/

The Washington Post (2020, 21/11). Fatal

Force tietokanta. Saatavilla:

https://www.washington-

post.com/graphics/investigations/policeshootings-database/
U.S. Department of Justice (2020, 26/10). Statistical Briefing Book. Office of Justice Programs. Saatavilla:

https://www.oj-

jdp.gov/ojstatbb/crime/ucr.asp?table_in= 2\&se-

1Yrs=2018\&rdoGroups=1\&rdoData=rp 